УДК 37.026.4

\title{
БИОЛОГИЧЕСКАЯ СОСТАВЛЯЮЩАЯ ЕСТЕСТВЕННОНАУЧНОЙ ГРАМОТНОСТИ ШКОЛЬНИКОВ
}

\author{
Арбузова Елена Николаевна \\ д.П.н., профессор
}

Яскина Ольга Александровна

ГОУ ВО МО «Московский государственный областной университет»

Аннотация: В статье рассматривается интегрированная модель SAMR и таксономия Блума, показаны возможности использования модульной технологии обучения при формировании биологической составляющей естесвтеннонаучной грамотности школьников.

Ключевые слова: естественнонаучная грамотность, модель SAMR, таксономия Блума, модуль, модульная программа.

\section{BIOLOGICAL COMPONENT OF THE NATURAL SCIENTIFIC LITERACY OF SCHOOLCHILD}

\section{Arbuzova Elena Nikolaevna Yaskina Olga Alexandrovna}

\begin{abstract}
The article examines the integrated SAMR model and Bloom's taxonomy, shows the possibilities of using modular teaching technology in the formation of the biological component of the natural scientific literacy of schoolchildren.

Key words: science literacy, SAMR model, Bloom's taxonomy, module, modular program.

Актуальной для современной школы является проблема формирования естественнонаучной грамотности у школьников, в частности ее биологической составляющей. На уроках биологии важным является не просто увеличение объема знаний обучающегося, а приобретение им разностороннего опыта деятельности. Задачей учителя является организация процесса повышения грамотности, составляющих основу в формировании естественнонаучной грамотности у учащихся.
\end{abstract}


Обновленное содержание образования требует внедрения новых современных технологий, методов, приемов, форм работы и средств обучения, которые направлены на формирование естественнонаучной грамотности учащихся.

Важными средствами, используемыми при формировании биологической составляющей естественнонаучной грамотности учащихся, являются применение в процессе обучения современных инновационных технологий, знаково-символических средств, демонстраций новизны исследуемого материала, используя внутри- и межпредметные связи в образовательном процессе.

Электронные средства обучения не всегда способствуют повышению качества образования. Для того чтобы правильно определить место и возможности внедрения современных технологий в образование используется модель SAMR (Substitute, Augmentation, Modification, Redefinition), предложенная Рубеном Р. Пуэнтедором [1]. Основная цель модели помочь учителю создать, усовершенствовать и внедрить в учебный процесс современные цифровые технологии для повышения успешности и производительности труда школьников. Модель состоит из четырех этапов, каждый из которых имеет свои особенности. Первый этап - замена (substitute). Средства информационных технологий используют для выполнения тех же самых действий, что и ранее, до компьютеров. Например, учащиеся вместо шариковой ручки используют компьютер и текстовый редактор, с помощью которого набирают и распечатывают тексты. Второй этап - накопление (augmentation). В данном случае информационные технологии используются для улучшения достижений. Например, школьники выполняют тестовые задания с помощью Google-форм вместо того, чтобы записывать ответы на бумаге.

Третий этап - модификация (modification). На данном этапе технологии используются для изменения и усовершенствования заданий. Примером является использование онлайн инструментов для совместной работы, публикация результатов в сети их обсуждение и совместное улучшение.

Четвертый этап - преобразование (redefinition). Здесь решаются педагогические задачи, которые невозможно решить без информационных технологий. Например, в условиях дистанционного обучения школьники создают свой блог, цифровой журнал.

При определении места и значения информационных технологий в образовании многие специалисты соотносят модель SAMR с таксономией Блума (рис. 1). 


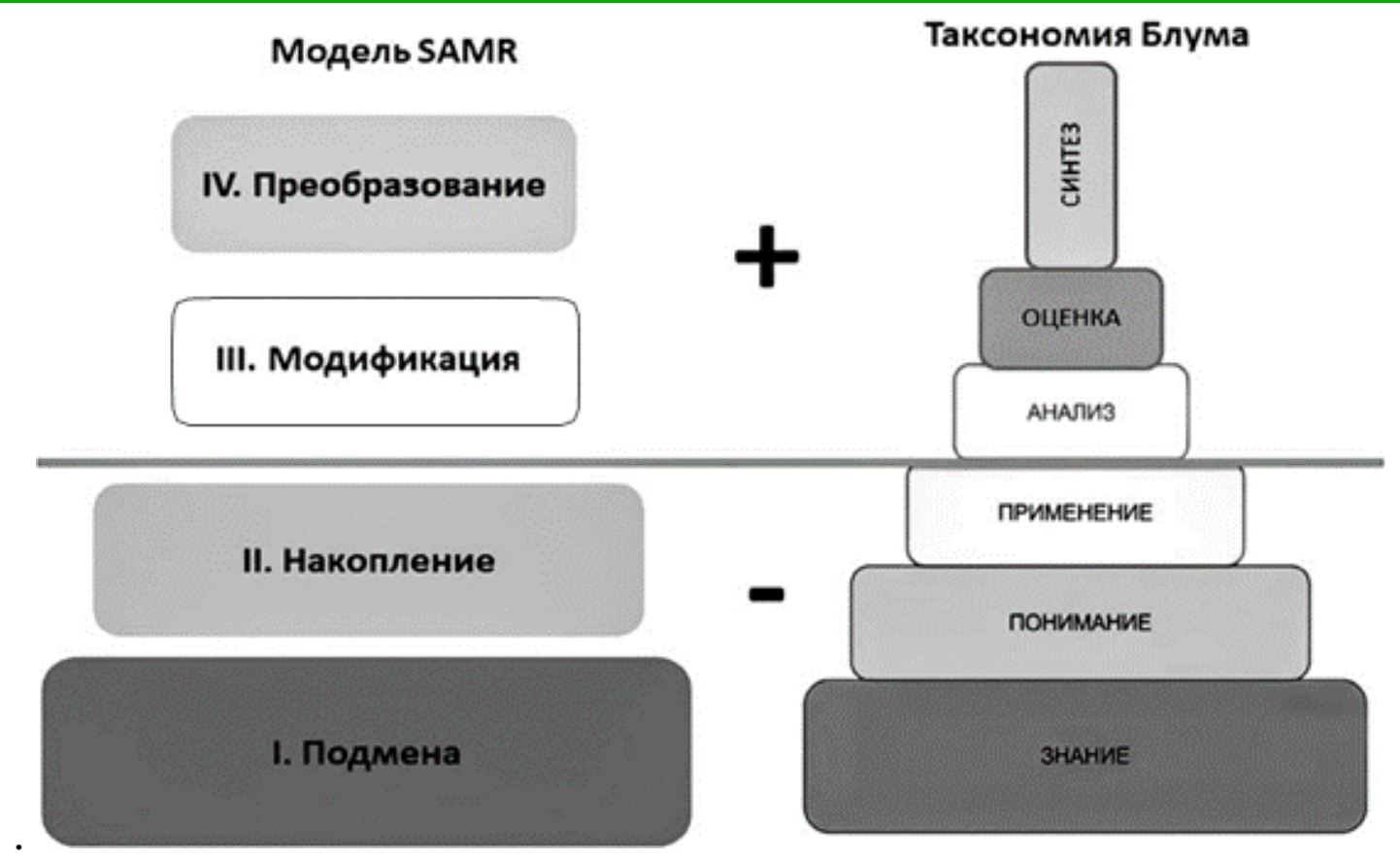

\section{Рис. 1. Интеграция модели SAMR и таксономии Блума}

Смысл этой интеграции заключается в том, что уровень использования информационных технологий может быть связан с достижением конкретных учебных целей. Например, замена информационными технологиями привычных действий на первом уровне (подмена), приводит к пассивному восприятию информации. При таком подходе происходит лишь запоминание фактического материала (1 уровень таксономии Блума).

На втором уровне SAMR (накопление) школьники уже могут переводить материал из одной формы в другую, применять его по шаблону. Это соответствует 2 и 3 уровням таксономии Блума.

Третий и четвертый уровни SAMR (модификация и преобразование) предполагают анализ информации, создание нового, оценивание результатов работы других учащихся, обсуждение высказанных идей. Это соответствует 4, 5 и 6 уровням таксономии Блума. На этих уровнях целесообразнее всего применять информационные технологии.

Результаты обучения должны включать различные уровни таксономии Блума, как правило, поднимая планку до высоких степеней иерархии. В этой связи, на наш взгляд актуальна модульная технология обучения. Данная технология положена в разработку учебных модулей по биологии. Обучающиеся используют модульную программы учебного занятия индивидуально, в парах постоянного и сменного состава, в малой группе [2].

В начале работы школьников по разработанному учителем модулю необходимо провести консультацию с использованием вводной карты как средства обучения. 


\section{Вводная карта к МП 10-19}

\section{Задание 1}

Прочитайте пословицу и дайте свое интеллектуальное (как понимаете) и/или эмоциональное (как чувствуете) объяснение.

Последовательность выполнения (алгоритм):

- пословица прочитана;

- пословица понята и есть эмоциональный отклик;

- дано объяснение себе, соседу и, возможно, всей учебной группе. «Все, что неожиданно изменяет нашу жизнь, - не случайность.

Оно - в нас самих и ждет лишь внешнего повода для выражения действием».

В. Брюсов

\section{Задание 2}

\section{Что общего у изображенных объектов?}
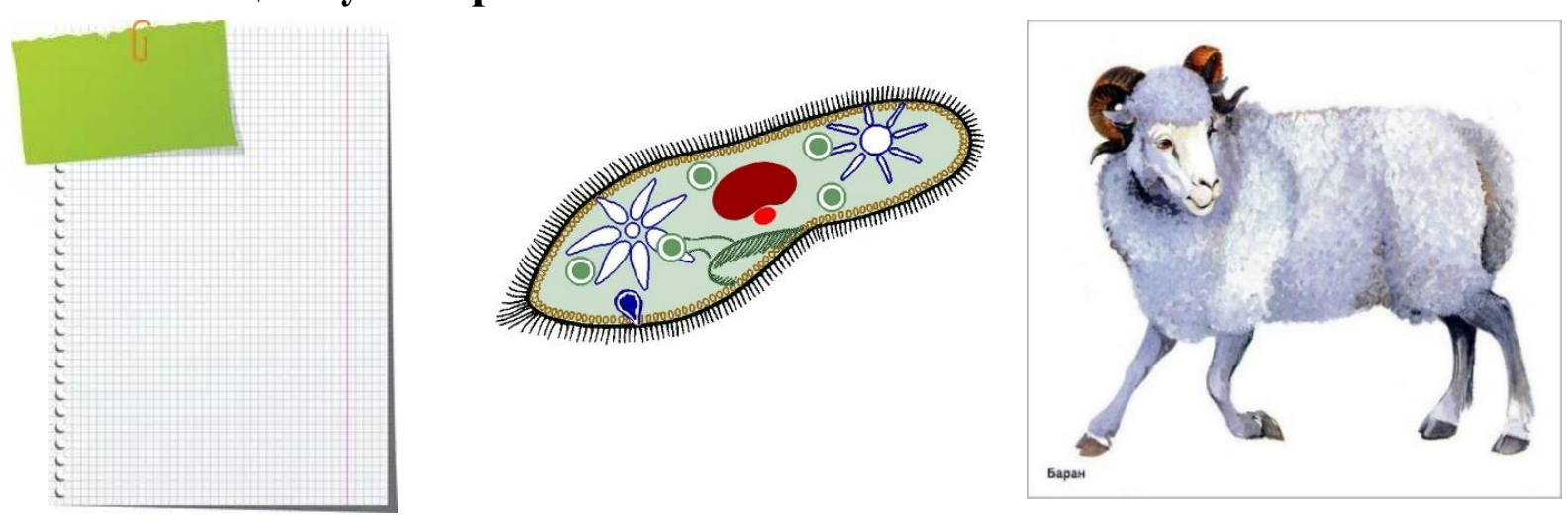

\section{Задание 3}

Разгадайте ребус

\section{9}

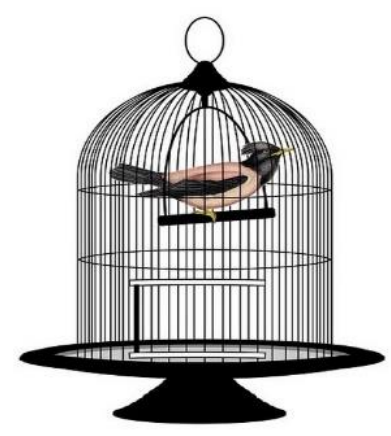

\section{СТАВКА}

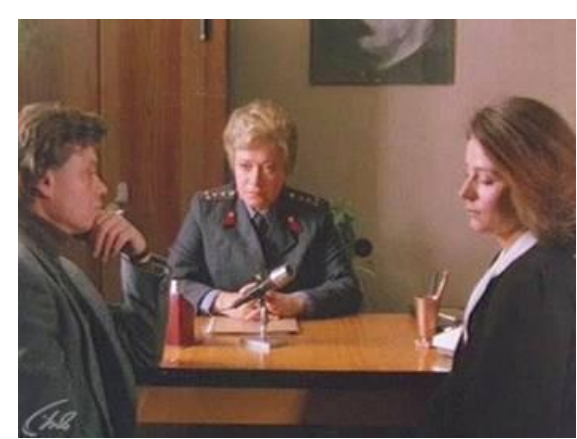

\section{ТЕОРИЯ}


Задание 4

Какова возможная тема учебного занятия?

Какова Ваша цель?

Что Вы сможете узнать?

Чему научиться?

Как сможете продолжить развивать коммуникативные навыки и саморегуляцию?

Критерии:

- в теме учебного занятия присутствует слово

- даны ответы на пять вопросов;

- цели записаны в рабочую тетрадь.

\section{Задание 5}

С какими школьными предметами связана данная тема?

Как связана тема учебного занятия с вашим пребыванием в исправительном учреждении?

Как она связанна с жизнью на свободе?

Где вы можете применить полученные знания и умения?

Критерии:

- даны ответы на четыре вопроса для себя, возможно, для других.

\begin{tabular}{|c|c|}
\hline (6) & $\begin{array}{l}\text { МП 10-19 Клеточный уровень: общая характеристика. } \\
\text { Клеточная теория }\end{array}$ \\
\hline
\end{tabular}

\section{〈! Зачет через 16 занятий $\downarrow$}

Определите для себя содержание иеели учебного занятия: что хотите узнать или чему научиться?

\begin{tabular}{l|l|l}
\hline $\begin{array}{l}\text { Последовательность } \\
\text { (алгоритм) }\end{array}$ & с Цели/результат, & Критерии: \\
определения & предложенные учителем: & - записано, что знать; \\
цели/результата: & - Знать основные методьl & - записано, что \\
- понять & изучения клетки; основнье & уметь; \\
содержание & положения клеточной теории. & - записано, что \\
учебной цели; & - Уметь объяснять & развивать. \\
- выбрать & необходимость знаний o & \\
\hline
\end{tabular}




\begin{tabular}{|l|l|l|}
\hline \hline содержание & понимания единства строения & \\
учебной цели; & и функционирования & \\
- принять & органического мира. & \\
содержание & - Развивать умение работать с & \\
учебной цели. & информацией и управлять & \\
& своими мыслями, чувствами, & \\
& состояниями, поведением. $\downarrow$ & \\
\hline \multicolumn{2}{|l|}{ ЗАПИШИТЕ В РАБОЧЕЙ ТЕТРАДИ СОДЕРЖАНИЕ УЧЕБНОЙ ЦЕЛИ } \\
\hline
\end{tabular}

\begin{tabular}{|c|c|c|}
\hline \multicolumn{3}{|c|}{ (-) Oпределите уровень учебной иели: } \\
\hline \multirow{4}{*}{$\begin{array}{l}\text { Последовательность } \\
\text { (алгоритм) } \\
\text { определения уровня } \\
\text { учебной цели: } \\
\text { - понять смысл } \\
\text { уровня учебной цели; } \\
\text { - выбрать уровень; } \\
\text { - соотнести } \\
\text { выбранный уровень } \\
\text { учебной цели с } \\
\text { содержанием } \\
\text { учебной цели. }\end{array}$} & Уровень учебной цели: & $\begin{array}{l}\text { Критерии: конкретные } \\
\text { действия учащихся, } \\
\text { свидетельствующие о } \\
\text { достижении данного } \\
\text { уровня }\end{array}$ \\
\hline & $\begin{array}{l}\text { 1. Знание (запоминание и } \\
\text { воспроизведение изученного } \\
\text { материала -от конкретных } \\
\text { фактов до целостной теории). }\end{array}$ & $\begin{array}{l}\text { воспроизводит термины, } \\
\text { конкретные факты, } \\
\text { методы и процедуры, } \\
\text { основные понятия, } \\
\text { правила и принципы. }\end{array}$ \\
\hline & $\begin{array}{l}\text { 2. Понимание } \\
\text { (преобразование материала из } \\
\text { одной формы выражения в } \\
\text { другую, интерпретация } \\
\text { материала, предположение о } \\
\text { дальнейшем ходе явлений, } \\
\text { событий). }\end{array}$ & $\begin{array}{l}\text { - объясняет факты, } \\
\text { правила, принципы; } \\
\text { - преобразует словесный } \\
\text { материал в } \\
\text { математические } \\
\text { выражения; } \\
\text { - предположительно } \\
\text { описывает будущие } \\
\text { последствия, } \\
\text { вытекающие из } \\
\text { имеющихся данных. }\end{array}$ \\
\hline & $\begin{array}{l}\text { 3. Применение (умение } \\
\text { использовать изученный } \\
\text { материал в конкретных } \\
\text { условиях и новых ситуациях). }\end{array}$ & $\begin{array}{l}\text { - применяет законы, } \\
\text { теории в конкретных } \\
\text { практических ситуациях; } \\
\text { - использует понятия и } \\
\text { принципы в новых } \\
\text { ситуациях. }\end{array}$ \\
\hline
\end{tabular}




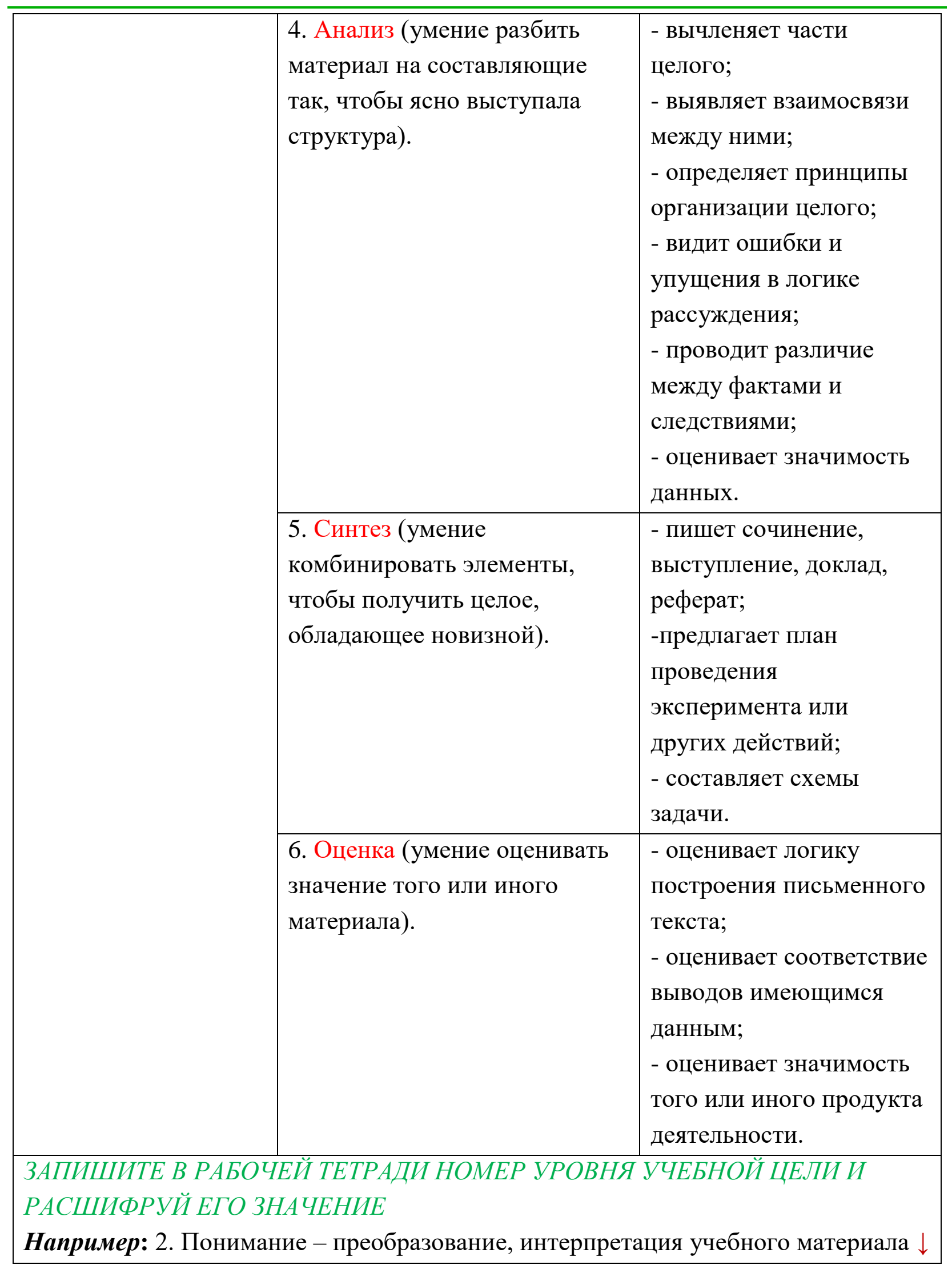


Упражнение № 1. Выполняется индивидуально.

Выясните, какие элементы содержания учебного материала Вам известны? Как они связанны с ранее изученныл или другими предметами?

\begin{tabular}{l|l|l}
\hline Алгоритм определения элементов & Например: & Критерии: \\
содержания учебного материала: & - борьба за существование; & - сделаны \\
- выписать знакомые понятия в & - формы борьбы за & две записи. \\
один столбик (левый); & существование. & \\
- выписать незнакомые понятия в & & \\
другой столбик (правый). &
\end{tabular}

Оставьте место рядом для расшифровки его значения (словарь терминов) по мере чтения опорного конспекта.

Hanpuмер: органоиды - это структуры клетки, выполняющие различные функции. $\downarrow$

\begin{tabular}{|l|l|}
\hline Известные мне понятия: & Неизвестные мне понятия: \\
1. & 1. \\
2. & 2. \\
\hline
\end{tabular}

Упражнение № 2. Выполняется индивидуально.

Прочитайте § 15 учебника стр. 110 и выпишите в рабочую тетрадь значения неизвестных для Вас понятий [2]个

Алгоритм:

- прочитать полностью текст параграфа учебника;

- понять текст и обсудить в паре/малой группе;

- выписать в рабочую тетрадь неизвестные понятия. $\downarrow$

Упражнение № 3. Выполняется индивидуально, в паре или группе обучающихся.

Запишите в рабочей тетради определение, заполнив пропуски слов в предложении. [1] $\underline{\imath}$

\begin{tabular}{|l|l|l|}
\hline Алгоритм выполнения & Изучением строения & Критерии: \\
упражнения: & клетки и принципами & - найдены два \\
- прочитать предложение; & ее ........... & пропущенных \\
- найти пропущенные слова; & занимается наука & слова. \\
- записать в рабочей & $\ldots \ldots \ldots \ldots . .$. & \\
тетради определение. & & \\
\hline
\end{tabular}


Упражнение № 4. Выполняется индивидуально, в паре или группе обучающихся.

Заполните в рабочей тетради таблииу, используя содержание § 15 учебника стр. 110 [1]

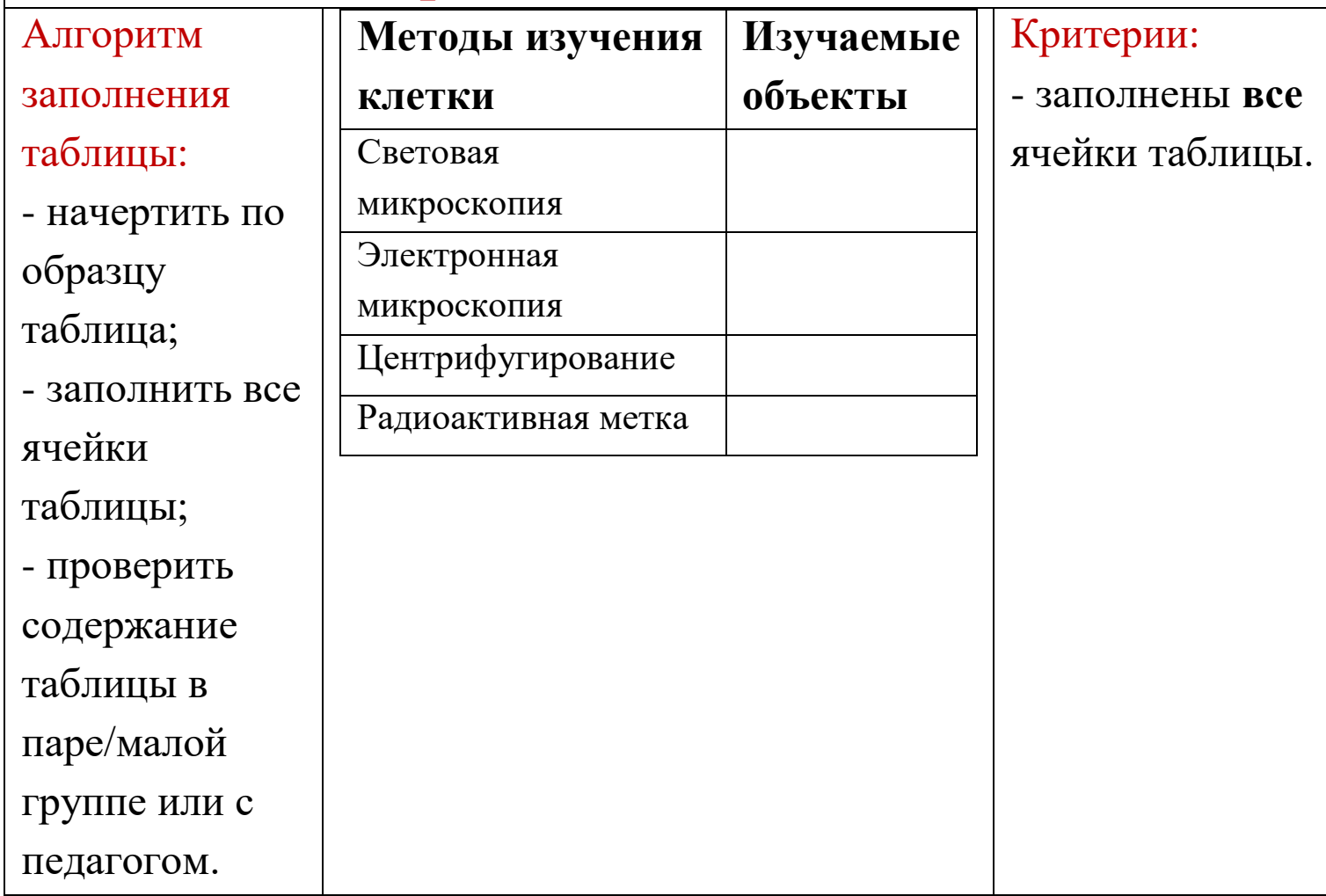

Упражнение № 5. Выполняется индивидуально, в паре или группе обучающихся.

Заполните в рабочей тетради таблииу, используя содержание § 15 учебника стр. $110[1] \uparrow$

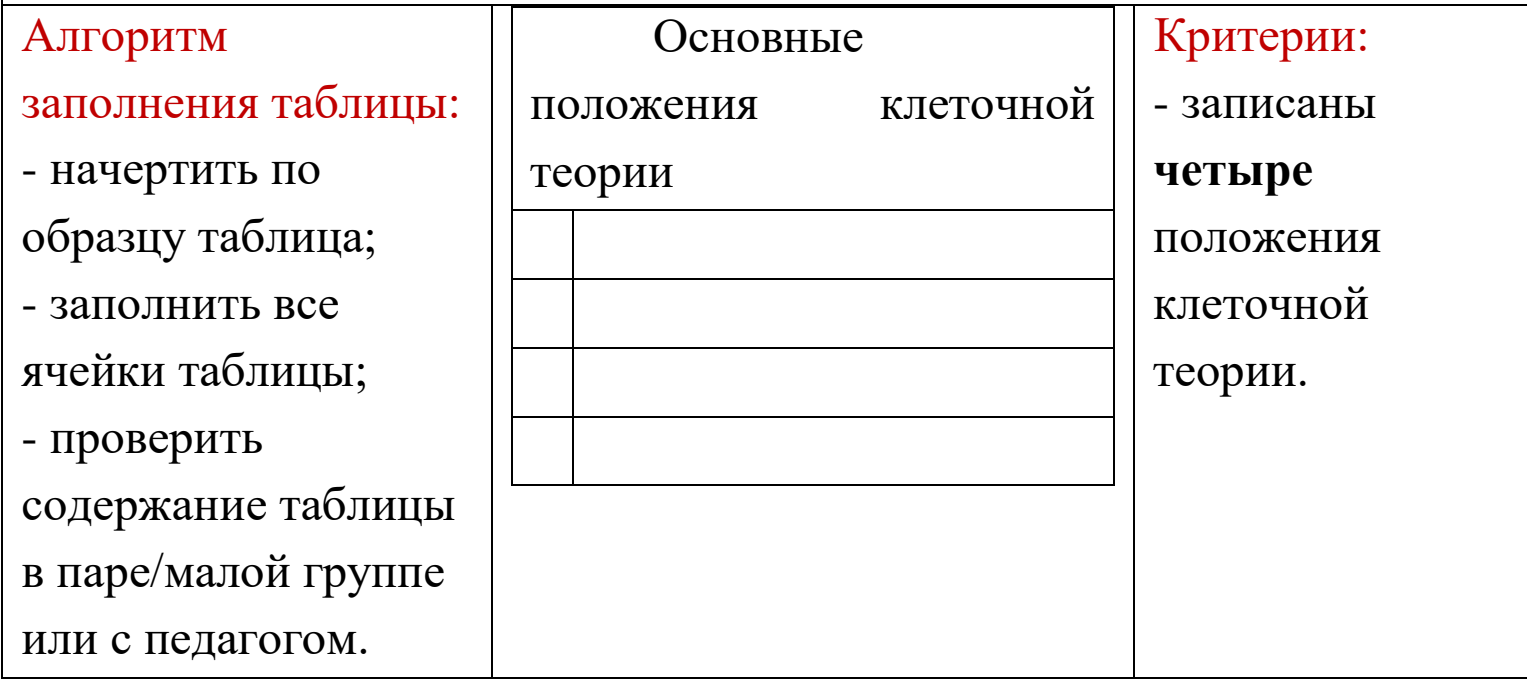


Упражнение № 6. Выполняется индивидуально, в паре или группе обучающихся.

Запишите в рабочей тетради задание и ответ на вопрос. [2] $\downarrow$

\begin{tabular}{|l|l|l|}
\hline Алгоритм выполнения & Согласны ли вы с & Критерии: \\
упражнения: & утверждением, что & - ответ записан в \\
- прочитать задание; & клеточная теория & тетради. \\
- понять задание; & доказывает единство & \\
- записать в рабочей текст & органического мира? & \\
вопросов; & Поясните свой ответ. & \\
- записать в рабочей тетради \\
ответы на вопросы.
\end{tabular}

Выполните творческое задание. Выполняется индивидуально, в паре или группе обучающихся.

Составьте интеллект-карту, которая отражает изученную Вами тему. [5] $\downarrow$

Алгоритм составления

интеллект-карты:

1. Берем лист бумаги и цветные карандаши, ручки или фломастеры.

2. Кладем лист горизонтально и в его центре, картинкой или одним - двумя словами, обозначаем основное понятие. Обводим это понятие в рамку или в кружок.

3. От иентрального объекта рисуем в разные стороны ветви - основные связанные с ним понятия, свойства, ассоциации, аспекты. Подписываем каждую одним-двумя словами, разборчиво, желательно даже печатными буквами.

4. От каждой ветви рисуем несколько более тонких

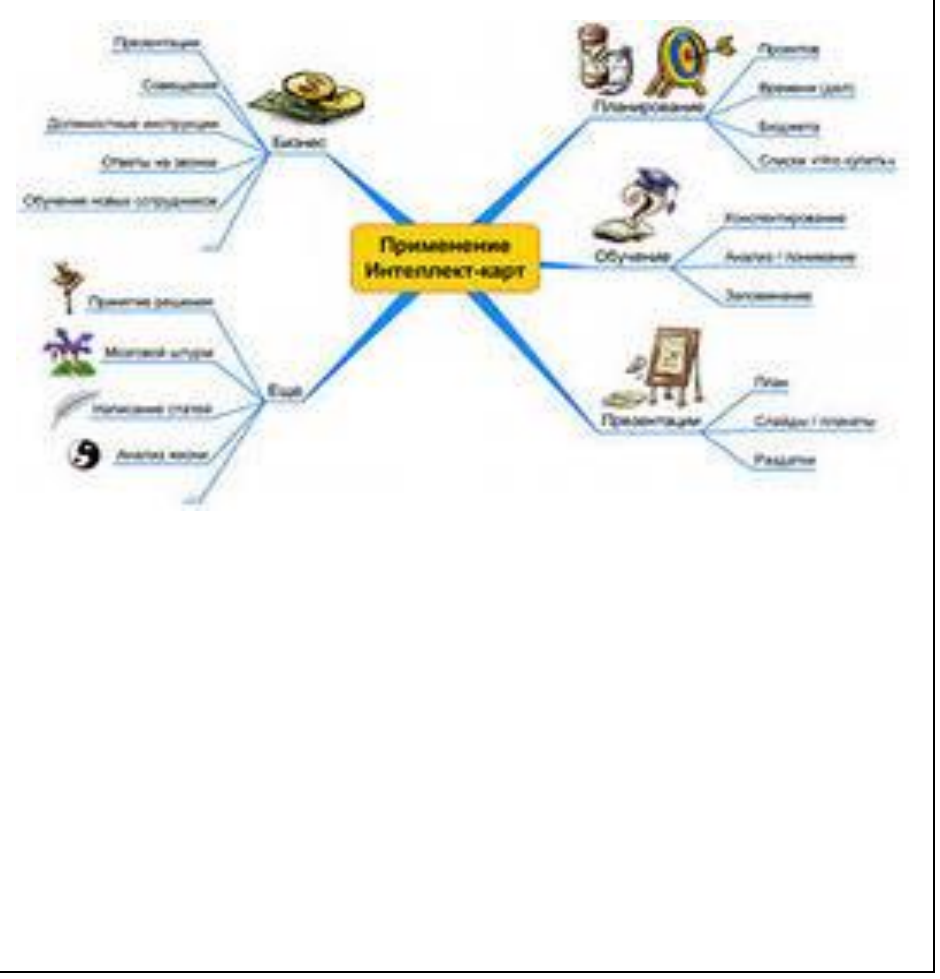


веточек - развитие ассоциаций, уточнение понятий, детализация свойств, конкретизация направлений.

5. Смысловые блоки отделяем линиями, обводим в рамку (не забываем про цвета).

6. Связи между элементами интеллект-карты показываем стрелками (тоже разного цвета и толщины).

\begin{tabular}{|c|c|c|}
\hline \multicolumn{3}{|c|}{ (:) Проведите самоанализ деятельности на учебном занятии. [6] $\downarrow$} \\
\hline $\begin{array}{l}\text { Алгоритм } \\
\text { самоанализа: } \\
\text { - прочитать } \\
\text { вопросы; } \\
\text { - понять } \\
\text { вопросы; } \\
\text { - найти } \\
\text { ответы на } \\
\text { вопросы. }\end{array}$ & $\begin{array}{l}\rightarrow \text { Каковы ваши главные результаты, } \\
\text { достигли ли цели занятия? } \\
\rightarrow \text { Что нового узнали, что вы поняли, } \\
\text { чему научились? } \\
\rightarrow \text { Какие задания вызвали наибольший } \\
\text { интерес и почему? } \\
\rightarrow \text { Как вы выполняли задания, какими } \\
\text { способами? Что вы чувствовали при } \\
\text { этом? } \\
\rightarrow \text { С какими трудностями вы столкнулись } \\
\text { и как вы их преодолевали? } \\
\rightarrow \text { Каковы замечания и предложения на } \\
\text { будущее (себе, педагогам, } \\
\text { организаторам)? } \\
\rightarrow \text { Оцените свою работу на учебном } \\
\text { занятии (удовлетворительно, } \\
\text { неудовлетворительно, хорошо, отлично). }\end{array}$ & $\begin{array}{l}\text { Критерии: } \\
\text { - даны ответы на } \\
\text { семь вопросов; } \\
\text { - выбрана одна } \\
\text { из оценок. }\end{array}$ \\
\hline
\end{tabular}

Опыт применения модульных программ на уроках биологии в школе показал, что при этом повышается успеваемость и качество обучения, а также способствует формированию биологической составляющей естественнонаучной грамотности школьников. 


\section{Список литературы}

1. Суматохин С.В. Биологическое образование в школе цифрового века // Биология в школе. 2020. № 6. С. 13-22.

2. Третьяков П.И. Технология модульного обучения в школе: Практикоориентированная монография / П.И. Третьяков, И.Б. Сенновский. - М. : Новая шк., 1997. - 350 с. 